\title{
КЛИНИКО-МОРФОЛОГИЧЕСКИЕ ПАРАЛЛЕЛИ ПРИ СЕНСОНЕВРАЛЬНОЙ ТУГОУХОСТИ, ОБУСЛОВЛЕННОЙ АКУВИБРАЦИОННЫМ ВОЗДЕЙСТВИЕМ
}

\author{
(С) Лобзина Е.В. ${ }^{1}$, Овсянников В.Г. ${ }^{2}$, Золотова Т.В. \\ ${ }^{1}$ Поликлиника № 3 Дорожной клинической больницы на станции Ростов - Главный ОАО «РЖД», \\ Ростов-на-Дону; ${ }^{2}$ кафедра патологической физиологии, ${ }^{3}$ кафедра болезней уха, горла, носа \\ Ростовского государственного медицинского университета, Ростов-на-Дону \\ E-mail: zolotovatatvik@gmail.com
}

\begin{abstract}
Проведено клинико-экспериментальное исследование для выявления морфологических изменений в спиральном органе животных и возможности воздействия на морфологический субстрат заболевания у лиц с тугоухостью, обусловленной виброакустическим воздействием. В эксперименте участвовало 34 белых беспородных крысы. Клиническая часть включала аудиологическое обследование 127 железнодорожников. В эксперименте выделена группа интактных животных, группа крыс, подвергшихся воздействию шума и вибрации на фоне иммобилизации без лечения, группа крыс, подвергнутых тому же воздействию, но с одновременным лечением препаратом с сосудистым эффектом силденафил и группа крыс с тугоухостью, которые получали лечебный препарат отсроченно. Морфологические исследования улиток височных костей животных свидетельствовали о дистрофических изменениях в спиральном органе, признаках апоптоза клеток внутреннего уха и спирального ганглия. Медикаментозная терапия силденафилом была более эффективна при применении одновременно с воздействием и приводила к уменьшению выраженности морфологических изменений. У больных с сенсоневральной тугоухостью прием силденафила вызывал протективный эффект, сопоставимый с использованием традиционных лекарственных средств.
\end{abstract}

Ключевые слова: сенсоневральная тугоухость, шум и вибрация, акувибрационное воздействие, работники железнодорожного транспорта, моделирование тугоухости, морфологические нарушения в спиральном органе, лечение тугоухости.

\section{CLINICAL MORPHOLOGICAL PARALLELS IN SENSORINEURAL HEARING LOSS DUE TO EXPOSURE TO ACOUSTIC VIBRATIONS Lobzina E.V. ${ }^{l}$, Ovsyannikov V.G. ${ }^{2}$, Zolotova T.V. ${ }^{3}$ \\ ${ }^{1}$ Road Clinical Hospital at Rostov-Main Station, Rostov-on-Don; ${ }^{2}$ Department of Pathological Physiology, ${ }^{3}$ Department of ENT of Rostov State Medical University, Rostov-on-Don}

A clinical and experimental study was conducted to identify morphological changes in the spiral organ of animals and the possibility of exposure to the morphological substrate of the disease in persons with hearing loss due to vibroacoustic effects. The experiment involved 34 white mongrel rats. A clinical part included an audiological examination of 127 railroad employees. In the experiment, a group of intact animals, a group of rats was exposed to noise and vibration against the background of immobilization without treatment. The second group of rats was exposed to the same vibration and noise, but it got simultaneous treatment with the drug Sildenafil having the vascular effect. And the third group of rats with hearing loss received the therapeutic drug with a delay. The morphological study of the animals' temporal cochlea proved the degenerative changes in the spiral organ, the signs of cell apoptosis of the inner ear and spiral ganglion. Drug therapy with Sildenafil was more effective when used simultaneously.

Keywords: sensorineural hearing loss, noise and vibration, vibroacoustic effect, railway workers, simulation of hearing loss, morphological disorders in the spiral organ, treatment of hearing loss, Sildenafil.

Влияние воздействия звуков и вибрации на организм человека и животных привлекает внимание исследователей на протяжении длительного времени $[6,7,11]$, но, несмотря на это, механизмы такого воздействия на внутреннее ухо и его последствия не полностью раскрыты. Статистические данные свидетельствуют о постоянном увеличении числа лиц с нарушениями слуха, приводящими к снижению работоспособности, ухудшению качества жизни [5].

Анатомо-физиологические особенности внутреннего уха, его топографическое расположение, наличие гематолабиринтного барьера затрудняют изучение этого органа у человека и его изменения при патологии и лекарственном воздействии. В связи с этим чрезвычайно важны экспериментальные исследования на животных [2, 12, 13, 15,] с изучением морфологических изменений и сопоставление их с клиническими данными у лиц, страдающих сенсоневральной тугоухостью (CHТ), в том числе вследствие виброакустического воздействия.

Считается, что сосудистые нарушения являются ведущим звеном в патогенезе заболевания при любой этиологии СНТ и, несмотря на отсутствие прямого воздействия на субстрат поражения, приводят к гипоксии, апоптозу, дистрофии структур слухового анализатора $[4,9]$. Это опре- 
деляет целесообразность коррекции сосудистых изменений при развитии СНТ, возникшей вследствие звукового и вибрационного воздействия.

Целью исследования явилось сопоставление морфофункциональных нарушений во внутреннем ухе лабораторных крыс после воздействия шума и вибрации и клинических данных у работников железнодорожного транспорта, получавших профилактическую терапию.

\section{МАТЕРИАЛЫ И МЕТОДЫ ИССЛЕДОВАНИЯ}

Исследование состоит из экспериментальной и клинической частей.

Работа по моделированию патологии внутреннего уха у животных и морфологические исследования проводились на кафедре патологической физиологии и в Центральной научноисследовательской лаборатории Ростовского государственного медицинского университета г. Ростова-на-Дону (РостГМУ). В эксперименте участвовали 34 белых беспородных половозрелых крысы-самца. Возраст 2-3 месяца. Масса тела 180-220 граммов. Лабораторные опыты с участием животных соответствовали международными этическим принципам и нормам проведения эксперимента.

Моделировали сенсоневральную тугоухость (CHТ) у белых беспородных крыс. Исследовали слуховую функцию животных и после формирования тугоухости выводили крыс из эксперимента. Готовили гистологические препараты внутреннего уха крыс и определяли гистологические изменения во внутреннем ухе лабораторных животных после шумовибрационного воздействия. Кроме того, исследовали влияние препарата силденафил на морфологию внутреннего уха крыс. Выделены следующие группы животных: 1-я группа - 6 здоровых интактных белых беспородных крыс; 2-я группа - 14 крыс, которым осуществляли воздействие для моделирования тугоухости; 3-я группа -8 крыс, которым моделировали тугоухость и одновременно проводили лечение с применением медикаментозного средства силденафил (одномоментное лечение), 4-я группа - 6 крыс, которых подвергали воздействию раздражителей, добиваясь нарушения слуха, а затем проводили лечение препаратом силденафил (отставленное лечение). Силденафил вводили «per os» с питьевой водой из расчета 1,25 мг/кг. У всех 34 лабораторных животных 68 ушей - для оценки состояния слуха и наблюдением изменений в динамике определяли рефлекс Preyer и регистрацию задержанной вызванной отоакустической эмиссии (ЗВОАЭ) и отоакустической эмиссии на частоте продуктов искажения (ОАЭЧПИ) с использованием прибора
«OtoRead» фирмы «Interacoustics» (Дания).

У белых беспородных крыс 1-й группы контроля исследовали слух и после забоя и приготовления гистологических препаратов внутреннего уха изучали интактный спиральный орган. Животных 2-й группы 1 раз в день иммобилизировали, помещая в одноместную клетку, и в течение 15 минут проводили акустическое воздействие широкополосным шумом частотой 355-5000 Гц с интенсивностью 90 дБ в свободном звуковом поле (Патент № 2627155) [1, 14], и дополнительно подвергали вибрационному воздействию. Такой комбинированный раздражитель использовали ежедневно на протяжении 10 суток. Особенность вибрационного воздействия заключалась в использовании вибрационного стенда «Аппарат для встряхиваний АВУ-6С», После окончания акустического и вибрационного воздействия иммобилизацию экспериментального животного прекращали. Животным оценивали слуховую функцию и выводили из опыта на 3-и, 10 -е и 20 -е сутки от начала эксперимента. Животных 3-й группы ежедневно 1 раз в день подвергали такому же воздействию, как во 2-й группе, но одновременно проводили лечение силденафилом в течение 10 суток, после чего выводили крыс из эксперимента. Животных 4-й группы в течение 10 суток ежедневно 1 раз в день подвергали такому же воздействию, как во 2-й группе, и после его окончания осуществляли лечение силденафилом 10 дней, после чего выводили крыс из эксперимента. В соответствии с условиями и сроками воздействия по группам животных производили забой крыс под наркозом в учетом принципов гуманного отношения к животным при проведении биомедицинских исследований. Височные кости крыс выделяли и обрабатывали по методике В.Ф. Аничина [1], затем готовили срезы улиток внутреннего уха, окрашивали гематоксилиномэозином и проводили гистологическое исследование с использованием метода световой микроскопии.

Клиническая часть работы включала обследование 127 больных с сенсоневральной тугоухостью, подвергающихся регулярно действию шума или шумовибрационному воздействию. Возраст больных - 18-60 лет. Длительность заболевания от 1 года до 35 лет. Стаж работы в условиях шума - от 5 до 30 лет. Исследование слуховой функции проводили методом тональной пороговой аудиометрии, импедансометрии.

В исследовании оценивались результаты межгрупповых различий и внутригрупповая динамика. Статистический анализ проводили с применением непараметрических критериев, используемых для малых выборок, независящих от характера распределения - точного критерия Фишера, критерия Вилкоксона. Использовали пакет при- 
кладных программ STASTISTICA 10, «Microsoft Excel».

\section{РЕЗУЛЬТАТЫ ИССЛЕДОВАНИЯ И ИХ ОБСУЖДЕНИЕ}

Экспериментальная часть. При исследовании слуховой функции в контрольной - 1-й группе животных и всех экспериментальных крыс до начала комплексного воздействия зафиксирован нормальный слух в $100 \%$ случаев: живой, устойчивый рефлекс Preyer - у 34 крыс (68 ушей); «тест пройден» при исследовании ОАЭЧПИ и ЗВОАЭ - у 34 обследованных крыс (68 ушей).

Во 2-й группе на 10-е сутки комбинированного воздействия у всех крыс имел место отрицательный рефлекс Preyer и отрицательный результат регистрации ЗВОАЭ и ОАЭЧПИ («тест не прошёл»), что объективно подтверждало факт тугоухости. На 20-е сутки рефлекс Preyer не вызывался и результат регистрации ЗВОАЭ и ОАЭЧПИ был отрицательным, что подтверждало формирование стойкой тугоухости у этих крыс после прекращения действия раздражителя. Итак, в целом во 2-й группе к окончанию комплексного шумового, вибрационного и иммобилизационного воздействия и через 10 дней после его прекращения тугоухость сформировалась в $100 \%$ случаев.

В 3-й группе на фоне того же комплексного воздействия, что и во 2-й группе животных, одновременно проводили лечение силденафилом в течение 10 суток. В результате слуховая функция оказалась нарушенной у 2 крыс $(25,0 \%)$, на что указывало угасание рефлекса Preyer и отрицательный результат при исследовании ЗВОАЭ и ОАЭЧПИ. У других 6 крыс $(75,0 \%)$ имели место положительные результаты «одновременного лечения», соответствующие показателям слуха контрольной группы. После окончания воздействия и одновременного лечения крыс выводили из эксперимента.

В 4-й группе у всех крыс на 10-е сутки после ежедневного шумового и вибрационного воздействия на фоне иммобилизации было зафиксировано угасание рефлекса Preyer и отрицательный результат при регистрации ЗВОАЭ и ОАЭЧПИ, что свидетельствовало о формировании тугоухости. У этих животных после проведенного в течение 10 дней отсроченного лечения силденафилом показатели исследования слуха свидетельствовали об отрицательных результатах у большинства крыс - 5 (83,3\%), лишь у 1 крысы $(16,7 \%)$ слух улучшился. После окончания воздействия и проведенного отсроченного лечения крыс выводили из эксперимента.

При морфологическом исследовании приготовленных препаратов улиток белых беспород- ных крыс у всех животных 1-й контрольной группы гистологическое строение органа слуха животных, его структурных составляющих, морфофункциональное состояние эпителиальных, соединительнотканных и нейрональных компонентов соответствовали норме.

У всех экспериментальных крыс, подвергшихся действию раздражителей, при морфологическом исследовании препаратов улиток височных костей отмечены патологические изменения в структурах спирального органа и в спиральном ганглии различной степени выраженности в зависимости от условий моделирования.

Во 2-й группе животных морфологические исследования, проведенные после моделирования СНТ путем ежедневного воздействия шума и вибрации на фоне иммобилизации в течение 10 дней, показали, что отдельные внутренние волосковые клетки (ВВК) и большее количество наружных волосковых клеток (НВК) изменены с проявлением ранних признаков апоптоза, таких как маргинация хроматина, гиперхроматоз ядер. Вдоль всей улитки встречаются участки с отсутствием НВК. Сосудистая полоска отечна. Сосуды отличаются полнокровием, чаще расширены. Некоторые опорные клетки, участки спиральной связки слущены и формируют оксифильные шаровидные массы. Спиральная связка отечна, имеются участки, не содержащие клеток, определяется умеренная инфильтрация мононуклеарными лейкоцитами. Наиболее заметные изменения во 2-й группе отмечены в спиральном ганглии: нейроны имеют выраженные дистрофические изменения, находятся в состоянии апоптоза или цитолиза, имеют вакуолизированную цитоплазму, гиперхромные ядра. Только единичные нейроны имеют типичные светлые ядра с глыбками хроматина и ядрышками. Итак, проведенные морфологические исследования спирального органа во 2-й группе крыс, которым моделировали СНТ, свидетельствуют о гистологических признаках повреждения спирального органа, что подтверждает развитие у них перцептивных нарушений, характерных для СНТ.

При морфологическом исследовании в 3-й группе животных, при моделировании СНТ с использованием шумового, вибрационного воздействия, иммобилизации и одновременным введением животным силденафила «per os» в течение 10 дней, получены следующие результаты: ВВК не изменены, НВК на протяжении всего улиткового канала сохранены, но некоторые имеют признаки раннего апоптоза с подчеркнутым рельефом кариолеммы, иногда - маргинацией хроматина или гиперхромностью ядер (рисунок 1). 


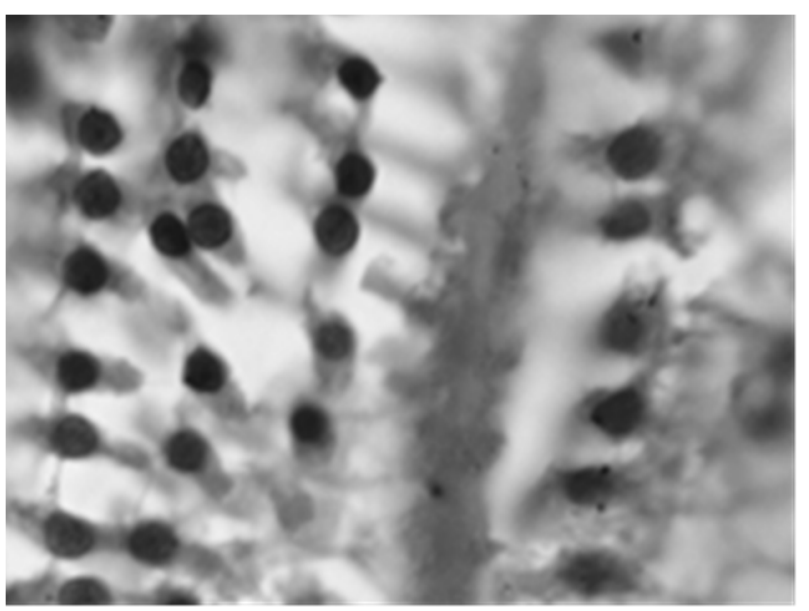

Рис. 1. Фрагмент спирального органа улитки крысы. Сохранность волосковых клеток при моделировании сенсоневральной тугоухости у крыс и одновременном применении силденафила. Окраска гематоксилином-эозином. Увеличение х1000.

Покровная мембрана имеет обычное строение. Опорные и поддерживающие клетки не изменены, но межклеточные пространства между наружными фаланговыми клетками несколько расширены. В просвете туннеля определяются нервные волокна. В сосудистой полоске отмечается слабовыраженный межклеточный отек. Сосуды расширены. Спиральная связка очагово отечна. В спиральном ганглии определяется небольшой отек стромы, набухание отдельных нейронов с вакуолизацией цитоплазмы и гиперхромностью ядер некоторых из них. Однако большинство нейронов имеют характерные для нервной ткани светлые ядра с небольшими глыбками хроматина и ядрышками.

В 4-й группе лабораторных животных, которым моделировали тугоухость и отсроченно использовали силденафил, выявлено, что ВВК не изменены, НВК сохранны, но некоторые имеют ранние признаки апоптоза, такие как подчеркнутая четкость кариолеммы, маргинация хроматина, гиперхроматоз ядер в клетках спирального органа. Межклеточные пространства между фаланговыми клетками расширены. Вспомогательные клетки дистрофически изменены, вакуолизированы, некоторые в состоянии цитолиза. Сосудистая полоска с признаками отека. Спиральная связка очагово отечна с уменьшением клеточности и с небольшой инфильтрацией мононуклеарными лейкоцитами. Эпителий спирального выступа и спиральной связки в состоянии лизиса. Нейроны спирального ганглия со слабовыраженным перицеллюлярным отеком, некоторые - набухшие, дистрофически изменены, с вакуолизированной цитоплазмой и гиперхромным ядром. В просвете барабанной лестницы встречаются эритроциты. Следовательно, отсроченное применение силденафила после шумовибрационного воздействия, хотя и не приводит к выраженному функциональ- ному эффекту в отношении слуха, но уменьшает выраженность морфологических изменений в спиральном органе, ссосудистой полоске, спиральном ганглии.

Таким образом, анализ гистологических препаратов показал, что морфологические признаки свидетельствуют о менее выраженном повреждении спирального органа при одновременном применении силденафила в сравнении с отсроченным его использованием у животных с нарушенным слухом.

Следует констатировать: проведенные морфологические исследования показали, что комбинированное воздействие шума, вибрации и иммобилизационного стрессирования при примененных нами условиях вызывает у экспериментальных белых беспородных крыс тугоухость. Этот факт, наряду с физиологическими аудиологическими тестами, подтверждается гистологическими признаками поражения спирального органа, такими как изменения НВК, преимущественно по пути апоптоза, выраженные повреждения нейронов спирального ганглия (значительный перицеллюлярный отек, набухание нейронов, апоптоз); наличие ранних апоптотических признаков в НВК, иногда - выпадения единичных НВК, признаки нарушений микроциркуляции, развития отеков различных структур, слущивание, цитолиз поддерживающих клеток и эпителиоцитов спиральной связки. При экспериментальном моделировании и развитии тугоухости у крыс отмечена эффективность медицинского препарата силденафил, что проявляется улучшением показателей микроциркуляции, выраженности патологических изменений в спиральном органе и степени поражения НВК и нейронов спирального ганглия. Полученные в эксперименте данные позволяют ожидать эффект от их использования для лечебно-профилактических целей у больных с СНT, 
особенно в случаях повышенной виброакустической нагрузки на слуховой анализатор человека.

Учитывая данные, полученные в экспериментальной части работы, нами было проведено клиническое исследование по изучению слуховой функции и результатов лечения у 127 больных с СНТ - работников железнодорожного транспорта, как известно, по роду деятельности подвергающихся воздействию шума и вибрации.

Симптомы СНТ имели место у всех 127 больных. Возрастная группа старше 50 лет оказалось наиболее многочисленной, составив $59,86 \%$ от общего числа обследованных. Стаж работы в условиях шума у обследованных лиц составил от 5 до 30 лет. Как показали анализ анамнестических данных и изучение материалов медицинских отчетов, в $31 \%$ случаев работники железнодорожного транспорта, у которых была зафиксирована CHT, работали на объектах, не соответствующих гигиеническим нормативам по уровню шума.

По результатам тональной пороговой аудиометрии, проведенной 80 лицам, выделено 4 клинические группы - А, В, С, Д. У 68 обследованных (85\%) выявлена СНТ I-III степеней.

В группу А - 12 человек вошли лица с признаками воздействия шума на орган слуха $15,0 \%$. В группу В - 28 человек вошли больные с тугоухостью I степени - 35\%, группа С - 19 человек со II степенью тугоухости - 23,75\%, группа Д -21 человек с III степенью тугоухости - 26,25\%.

Лечение и профилактику прогрессирования тугоухости проводили по двум схемам: по первой схеме - 95 больных получали традиционную терапию, по второй схеме - 32 больным с тугоухостью назначали силденафил.

Схема традиционной терапии включала препараты из группы антихолинэстеразных средств (нейромидин), метаболическую терапию (мильгамма, мильгамма композитум), средства, улучшающие кровоснабжение и трофику тканей слухового анализатора, цитопротекторы (цитофлавин), нейропептидные средства (аудиоинвит, даларгин), а также проводилась эндоауральная или транскраниальная электростимуляция слуховых структур 1-2 раза в год.

Схема лечения с применением силденафила: для лечение 30 лиц из числа групп В, С, Д с подтвержденной сенсоневральной тугоухостью I-III степени назначали силденафил курсами по 25 мг в сутки (1 табл.) в течение 10 дней 2 раза в год. Наблюдение в течение 3 лет показало высокую эффективность используемой схемы. Эффект был подтвержден при тональной пороговой аудиометрии отсутствием прогрессирования тугоухости у всех обследованных лиц. Результаты лечения силденафилом пациентов по предлагаемой схеме были сопоставимы с результатами те- рапии традиционными методами: прогрессирования слуховых нарушений не наблюдалось.

Таким образом, проведенное исследование доказывает эффективность предложенного способа моделирования сенсоневральной тугоухости у белых беспородных крыс, основанного на комплексном воздействии шумового и вибрационного факторов на фоне иммобилизационного стрессирования по предложенной схеме и параметрам. Факт наступления тугоухости доказан двумя достоверными методами исследований: функциональным при регистрации различных видов отоакустической эмиссии и гистологическим при исследовании препаратов внутреннего уха височных костей животных с констатацией нарушений клеточных и мембранных структур спирального органа, достоверно подтверждающих сенсоневральные нарушения в $100 \%$ случаев. Морфологические данные, полученные при изучении препаратов улиток внутреннего уха после примененных условий воздействия, отличались признаками микроциркуляторных расстройств, выраженностью отека, наличием сладжа, нарушенным морфофункциональным состоянием различных тканей и клеток спирального органа, особенно нейронов спирального ганглия, что соответствует признакам вторичной транссинаптической нейродегенерации. Клеточные повреждения при примененных условиях шумовибрационного воздействия чаще наблюдались в виде апоптотических изменений, подобно тому, как это происходит при моделировании ототоксической СНТ по данным ряда исследований $[3,14,15]$. Что касается полученных нами данных о более выраженных морфологических нарушениях спирального ганглия, а не волосковых клеток, то они также согласуются с результатами исследований некоторых других авторов о приоритетном поражении нейронов спирального ганглия [10].

Учитывая выявленные механизмы патогенеза CHT, такие как апоптотические изменения клеток, сосудистые нарушения в спиральном органе, поиск лекарственных препаратов для лечения СНТ может быть направлен именно на коррекцию этих звеньев при акустическом и вибрационном повреждении внутреннего уха человека. Используя препарат силденафил в настоящем исследовании, мы рассчитывали на его сосудистое действие. Лишь в единичных зарубежных исследованиях имеются данные об использовании силденафила при акустической травме и его влиянии на внутреннее ухо.

Протективные свойства силденафила при лечении СНТ можно связать с уменьшением микроциркуляторных расстройств: выраженностью отеков, наличием сладжа, морфофункциональным состоянием различных тканей и клеток спираль- 
ного органа, но особенно нейронов спирального ганглия, как более повреждаемых и поэтому менее сохранившихся. Патология последних в нашем эксперименте при моделировании СНТ соответствует вторичной транссинаптической нейродегенерации.

Медикаментозная терапия силденафилом оказалась эффективной при его использовании у лабораторных крыс, подвергшихся действию шумовибрационного раздражителя в условиях иммобилизации, особенно при одновременном с моделированием применением силденафила. Силденафил, как средство с сосудистым эффектом, проявляет в эксперименте при шумовибрационном воздействии на крыс свойства протектора в отношении различных структур спирального органа, в том числе волосковых клеток и нейронов спирального ганглия, приводя к уменьшению выраженности морфологических нарушений в них. Клинические данные по применению силденафила для предотвращения прогрессирования СНТ у работников железнодорожного транспорта подтвердили результаты эксперимента на животных и могут быть связаны с воздействием на морфологический субстрат заболевания.

Следовательно, можно сделать вывод о возможности применения силденафила в качестве лечебно-профилактического средства при звуковых и вибрационных воздействиях на орган слуха человека с перспективой протекторного действия при угрозе возникновения и прогрессирования сенсоневральной тугоухости.

\section{ЛИТЕРАТУРА / REFERENCES}

1. Аничин В.Ф. Методы гистологической обработки ушного лабиринта // Архив анатомии, гистологии и эмбриологии. - 1978. - Т. 75, № 8. - С. 77-83. [Anichin V.F. Methods of histological processing of the labyrinth of the ear. Arkhiv anatomii, gistologii i embriologii. 1978; 75(8): 77-83 (in Russ.)].

2. Золотова Т.В., Овсянников В.Г., Лобзина Е.В., Дубинская Н.B. Моделирование сенсоневральной тугоухости в эксперименте // Российская оториноларингология. - 2018. - Т. 93, № 2. - C. 35-38. - DOI: 10.25207/1608-6228-2018-25-3-82-87. [Zolotova T.V., Ovsyannikov V.G., Dubinskaya N.V., Lobzina E.V. Simulation of sensoneural hearing loss in the experiment. Rossiyskaya otorinolaringologiya. 2018; 93(2): 35-38 (in Russ.)].

3. Золотова Т.В., Панченко С.Н. Экспериментальная сенсоневральная тугоухость ототоксического генеза у животных: апоптотический путь гибели клеток спирального органа. // Вестник оториноларингологии. - 2010. - № 4. - С. 29-32. [Zolotova T.V., Panchenko S.N. Experimental sensorineural loss of hearing of ototoxic origin in animals: apoptotic mechanism of cell death in the spiral organ. Vestnik otorinolaringologii. 2010; (4): 29-32 (in Russ.)].
4. Золотова Т.В. Сенсоневральная тугоухость. - Ростов н/Д. : ЗАО «Книга», 2013. - 544 с. [Zolotova T.V. Sensorineural hearing loss. Rostov-na-Donu : ZAO «Kniga»; 2013: 544 (in Russ.)].

5. Кудеева Я.Ю., Байбакова Е.В., Чугунова М.А., Резакова Н.В. Токсическое поражение внутреннего уха под воздействием цисплатина. Экспериментальное исследование // Российская оториноларингология. - 2015. - № 2 (75). - С. 43-47. [Kudeeva Y.Yu., Baybakova E.V., Chugunova M.A., Rezakova N.V. Cisplatin induced toxic impairment of inner ear. experemental trial in vivo cisplatin induced toxic impairment of inner ear. experemental trial in vivo. Rossiyskaya otorinolaringologiya. 2015; 75(2): 43-47 (in Russ.)].

6. Овсянников В.Г., Золотова Т.В., Лобзина Е.В., Дубинская Н.В. Патологические изменения во внутреннем ухе при экспериментальном моделировании сенсоневральной тугоухости у животных // Кубанский научный медицинский вестник. 2018. - T. 25, № 3. - C. 82-87. - DOI: 10.25207/1608-6228-2018-25-3-82-87. [Ovsyannikov V.G., Zolotova T.V., Lobzina E.V., Dubinskaya N.V. Pathological changes in the inner ear in experimental modeling of sensorineural hearing loss in animals. Kubanskiy nauchnyy meditsinskiy vestnik. 2018; 25(3): 82-87 (in Russ.)].

7. Пальчун В.Т., Гусева А.Л., Левина Ю.В., Чистов С.Д. Клинические особенности острой нейросенсорной тугоухости, сопровождающейся головокружением // Вестник оториноларингологии. - 2016. - Т. 81, № 1. - С. 8-12. - DOI: 10.17116/otorino20168118-12. [Pal'chun V.T., Guseva A.L., Levina Yu.V., Chistov S.D. The specific clinical features of acute sensorineural loss of hearing associated with vertigo. Vestnik otorinolaringologii. 2016; 81(1): 8-12 (in Russ.)].

8. Способ моделирования сенсоневральной тугоухости. Патент № 2627155, ФГБОУ ВО РостГМУ Минздрава России; заявка: 2016133837, 17.08.2016; публикация 03.08.2017. Бюл. № 22. [А way to simulate sensorineural hearing loss. Patent No. 2627155, Federal State Budget Educational Institution of Higher Education of Rostov State Medical University; application: 2016133837, 08/17/2016; publication 08/03/2017. Bul. No. 22 (in Russ.)].

9. Beurg M., Hafidi A., Skinner L., Cowan G., Hondarrague Y., Mitchell T.J., Dulon D. The mechanism of pneumolysin-induced cochlear hair cell death in the rat // J Physiol. - 2005. - Vol. 568, Pt. 1. - P. 211227. - DOI: 10.1113/jphysiol.2005.092478.

10. Fernandez K.A., Jeffers P.W., Lall K., Liberman M.C., Kujawa S.G. Aging after noise exposure: acceleration of cochlear synaptopathy in "recovered" ears // J Neurosci. - 2015. - Vol. 35, N 19. - P. 7509-7520. - DOI: 10.1523/JNEUROSCI.5138-14.2015.

11. Liang Y., Zhang S., Zhang X. Effect of sildenafil on morphology to noise-induced hearing loss in guinea pigs // Lin Chung Er Bi Yan Hou Tou Jing Wai Ke Za Zhi. - 2015. - Vol. 29, N 13. - P. 1216-1220. [(in Chinese)].

12. Müller M., Tisch M., Maier H. Löwenheim Begrenzung chronischer Hörverluste durch locale Gluko- 
kortikoidgabe Meerschweinchen mit akutem Lärmtrauma // HNO. - 2016. - Vol. 64, N 11. P. 831-840. - DOI: 10.1007/s00106-016-0256-1.

13. Wong A.C.Y., Froud K.E., Hsieh Y.S.Y. Noise-induced hearing loss in the $21^{\text {st }}$ century: A research and translational update // World Journal of Otorhinolaryngology. - 2013. - Vol. 3, N 3. - P. 58-70. - DOI: 10.5319/wjo.v3.i3.58.

14. Wong A.C., Ryan A.F. Mechanisms of sensorineural cell damage, death and survival in the cochlea // Front
Aging Neurosci. - 2015. - Vol. 7. - P. 58. - DOI: 10.3389/fnagi.2015.00058.

15. Wu C.M., Lee K.J., Chang S.L., Weng S.F., Lin Y.S. Recurrence of idiopathic sudden sensorineural hearing loss: a retrospective cohort study // Otol Neurotol. 2014. - Vol. 35, N 10. - P. 1736-1741. - DOI: 10.1097/MAO.0000000000000630. 